\title{
Evaluation of dietary intake in Danish adults by means of an index based on food-based dietary guidelines
}

\author{
Vibeke K. Knudsen*, Sisse Fagt, Ellen Trolle, Jeppe Matthiessen, \\ Margit V. Groth, Anja Biltoft-Jensen, Mette R. Sørensen and \\ Agnes N. Pedersen
}

Division of Nutrition, National Food Institute, Technical University of Denmark, Søborg, Denmark

Abstract

Background: Data on dietary intake and physical activity has been collected from a representative sample of the Danish population from 2003-2008.

Objectives: The aim of the present study was to describe the habitual diet in Denmark and to evaluate the overall diet quality using a diet quality index based on the National Food-Based Dietary Guidelines (FBDG), which consists of seven guidelines regarding diet and one regarding physical activity.

Design: Data from the Danish National Survey of Diet and Physical Activity 2003-2008 $(n=3354)$ were included. The diet quality index was constructed based on five of the seven dietary guidelines. Individuals were categorised according to quartiles of the diet quality index, and food and nutrient intakes were estimated in each of the groups.

Results: Macronutrient distribution did not meet recommendations in any of the groups, as energy from total fat and especially saturated fat was too high. A high intake of high-fat milk products, fat on bread and processed meat contributed to a high intake of total fat and saturated fat, and sugar-sweetened soft drinks contributed to a high intake of added sugars in the group below the lowest quartile of the diet quality index. Individuals above in the highest quartile had higher intakes of 'healthy foods' such as fish, fruit and vegetables, rye bread, and also a higher consumption of water and wine. Overall, intakes of micronutrients were sufficient in all groups.

Conclusions: The diet quality index is a useful tool in assessing food and nutrient intake in individuals with high vs. low degree of compliance towards the dietary guidelines, and provides a valuable tool in future studies investigating variations in dietary intakes with respect to lifestyle, demographic and regional differences in Denmark.

Keywords: diet habits; index; cross-sectional; 7-days pre-coded food diary; food-based dietary guidelines

Received: 2 January 2012; Revised: 16 March 2012; Accepted: 17 March 2012; Published: 20 April 2012

$\mathrm{E}$ ating a healthy diet may lead to improved quality of life and increased longevity (1), and guidelines on healthy eating habits are therefore essential in improving public health. In Denmark food-based dietary guidelines (FBDG) have existed since 1970'ties, and have undergone minor revisions during the past decades (2). They serve as instruments in coordinating public health messages related to diet and lifestyle, and consist in the present form of eight guidelines, seven on diet and one on physical activity (Table 1). The FBDG are based on the Nordic Nutrition Recommendations 2004 (NNR) (3) and on literature studies on food intake and health. However,
FBDG will only be beneficial for public health if they are followed by the population. Evaluation of the overall diet quality regarding food and nutrient intake of the population based on the compliance towards FBDG will give more insight in the public health status, and may provide valuable knowledge in developing and communicating dietary guidelines in the future.

It has previously been reported that only $3 \%$ follow the guidelines regarding intake of foods rich in saturated fat and fibre in Denmark (4), indicating that compliance towards FBDG is low. However, evaluating compliance with each of the guidelines separately does not illustrate 
Table 1. The eight dietary guidelines

\begin{tabular}{|c|c|}
\hline Dietary guideline & Food/nutrient included in index \\
\hline $\begin{array}{l}\text { Eat less fat - particularly fats from } \\
\text { meat and dairy products }\end{array}$ & $\begin{array}{l}\text { Max } 30 \mathrm{E} \% \text { from total fat, and } \\
\max 10 \mathrm{E} \% \text { from saturated fat }\end{array}$ \\
\hline $\begin{array}{l}\text { Eat potatoes, rice or pasta and } \\
\text { wholemeal bread - every day }\end{array}$ & Min $500 \mathrm{~g} /$ day \\
\hline $\begin{array}{l}\text { Eat fruit and vegetables every day }-6 \\
\text { portions/pieces per day }\end{array}$ & $\begin{array}{l}\text { Min } 600 \mathrm{~g} \text { fruits and vegetables/ } \\
\text { day }^{\mathrm{a}}\end{array}$ \\
\hline $\begin{array}{l}\text { Fish and fish products several times } \\
\text { a week }\end{array}$ & Min $200 \mathrm{~g}$ fish/week \\
\hline $\begin{array}{l}\text { Limit intake of sugar - particularly } \\
\text { from soft drinks, confectionary and } \\
\text { cakes }\end{array}$ & Max $10 \mathrm{E} \%$ from added sugar ${ }^{\mathrm{b}}$ \\
\hline $\begin{array}{l}\text { Eat a varied diet and maintain an } \\
\text { healthy body weight }\end{array}$ & (not included) \\
\hline Drink water when you are thirsty & (not included) \\
\hline $\begin{array}{l}\text { Engage in physical activity - at least } 30 \\
\mathrm{~min} / \text { day }\end{array}$ & (not included) \\
\hline
\end{tabular}

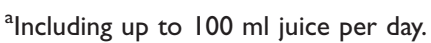

${ }^{b}$ Added sugar consists of industrially added sugar and sugar added in cooking or at the table, and thus includes sugar in candy, bakery and soft drinks.

the overall quality of the diet. One approach in evaluating overall diet quality is to rank individuals according to how they score on a diet quality index created on the basis of the FBDG. The approach of creating an index has been applied in previous studies (4-10), and deals with the complexity in the diet in contrast to exploring single foods and nutrients (11). Using such an approach enables a description and evaluation of the food and nutrient intake in groups of individuals with diets more or less in compliance with the FBDG, respectively.

In order to monitor compliance with the FBDG, dietary intake should be assessed at the population level. The Danish National Survey of Diet and Physical Activity is an ongoing, nation-wide, representative survey with the aim of monitoring status, trends and variations in dietary intake and physical activity in Denmark, as well as lifestyle factors and attitudes towards and determinants of dietary habits. The data collected in this survey thus provide a unique opportunity to evaluate overall diet quality and compliance with the FBDG in a representative sample of the adult Danish population.

The aims of this study were to develop a diet quality index based on the FBDG, and to evaluate the quality of the diet in a representative sample of the population by use of the diet quality index.

\section{Methods}

The study was based on data from the Danish National Survey of Diet and Physical Activity which comprises data on diet and physical activity in a representative sample of the Danish population. Furthermore, anthropometric, lifestyle and demographic data were available. Data were collected from 2003-2008, and include dietary as well as background information from 4,431 participants aged 4-75 years (12). Only data on the adult population (18-75 years) were included in this study, comprising 3,354 individuals, 1,569 males and 1,785 females.

Dietary intake was estimated by means of a pre-coded food diary completed by the participants for seven consecutive days. The food diary was structured as a typical Danish diet comprising breakfast, lunch, dinner and three snack meals with pre-coded lines of the most commonly eaten foods and drinks, and for each of the meals participants had the opportunity to write additional food and drink items not included in the pre-coded food diary. Portion sizes were estimated using household measures (cups, glasses, etc.), and 12 series of photographs with varying portion sizes of commonly eaten foods. Mean and median intakes of foods, macro-and micronutrients were calculated by use of the software system GIES developed at the National Food Institute including standard recipes, information of portion sizes and data from the Danish Food Composition Database (www.foodcomp.dk) as described previously (13). The pre-coded food diary has been validated against an objective measure of total energy expenditure $\left(\right.$ ActiReg ${ }^{\circledR}$, PreMed AS, Olso, Norway), and was found valid in estimating total energy intake, although mean intake of total energy intake was underestimated by $12 \%$ among adults $(13,14)$. Furthermore, a relative validation study showed moderate to good agreement between intakes reported in the pre-coded food diary and a weighed food record, both completed for four consecutive days, and showed that the food diary was able to rank individuals according to high and low intake of nutrients and food groups (15).

To evaluate the overall quality of the diet a diet quality index based on the FBDG's relating to dietary intake was developed. Cut-off values for reducing total fat, saturated fat and added sugar were applied. Following nutrients/ foods were included in the index (Table 1): Contribution of energy from total fat $(\max 30 \%)$, contribution of energy from saturated fat (max $10 \%$ ), energy from added sugar $(\max 10 \%)$, intake of potatoes, rice, pasta and wholemeal bread ( $\min 500 \mathrm{~g} /$ day), intake of fruit and vegetables ( $\min 600 \mathrm{~g} /$ day), and intake of fish (min $200 \mathrm{~g} / \mathrm{week}$ ). Added sugar consists of industrially added sugar and sugar added in cooking or at the table, and thus includes sugar in candy, bakery and soft drinks. The two dietary guidelines 'Eat a varied diet and maintain a healthy body weight' and 'Drink water when you are thirsty' were not included in the index due to the somewhat non-measurable nature of these guidelines. The diet quality index - adapted from $(8,16)$ - was 
constructed as follows: for each individual, a dietary score was calculated for each of the six nutrients/foods groups as the ratios between the actual intake and the recommended intake of the certain nutrient or food, e.g. if an individual eats $500 \mathrm{~g}$ fruit and vegetables per day, the score is $500 / 600=0.83$. For foods/nutrient with an upper limit of recommended intake the score was calculated as 1-[(intake-recommended)/recommended], thus for an individual with an intake of $37 \%$ energy from total fat the score was calculated as $1-[37 / 30]=0.77$. In individuals with intakes exceeding the cut-off values the individual was assigned the maximum score value of 1 , and no further nutritional value was added to the score. The score for each of the items included thus ranged from 0 to 1 , with zero assigned to the intake of a food or nutrient most far from the dietary guideline, and one for the intake complying with the guideline. The scores of the six foods and nutrients were summed to a total score with 0 as minimum and six as maximum score. To distinguish individuals close to following the dietary guidelines and those with less healthy diets, all individuals were afterwards categorised according to quartiles of score, and the two intermediary groups were combined, resulting in three groups in total. The reason for the intermediary group being twice as big as the two other groups is to get an appropriate range in scores as well as intakes in all three groups, as it is assumed that most of the individuals are centred in the middle of the score range, with fewer observations in the very low and very high end of the scale.

Intakes of foods and nutrients in each of the three groups of diet index were estimated. Mean and standard deviations were calculated for intakes of nutrients, and median as well as 25 and 75 percentiles were calculated for intakes of foods and food groups, due to the right skewed distribution of these. Trend test were performed using chi square test (Type III) with group of diet index included as continuous variable. Results were considered statistically significant at $p<0.05$. All data manipulation and statistical analysis were carried out in SAS Enterprise Guide version 4.1(17).

\section{Results}

Characteristics of the populations in the three groups defined by the total score of the diet quality index are presented in Table 2. Diet quality index score ranged from 1.2 to 6 , with a mean in the whole sample of 4.0 , and 2.8, 4.1 and 5.2 in each of the three groups. Age as well as proportion of females increased slightly with increasing score, and women had a higher mean score compared to men (4.2 vs. 3.8 ). No difference in body mass index (BMI) was seen between the groups. There was an increasing proportion of under-reporters, assessed as ratio of reported energy intake to basal metabolic rate (EI:BMR) less than 1.1 (18), with higher diet score.

Mean intakes of total energy intake, distributions of macronutrients and intakes of micronutrients in each of the three groups of diet quality index for both men and women are presented in Table 3. As expected, total energy intake and energy from fat decreased with increasing score, while energy from carbohydrate and protein increased with increasing score, as the proportion of energy from the three macronutrients are correlated. Only in the highest group among the women the recommended intake of energy from fat of maximum $30 \%$ was reached. Protein intake was close to recommended in all three groups in both genders, while wider variations were seen in contribution of carbohydrate (46 to $53 \mathrm{E} \%$ ). Both saturated and monounsaturated fat decreased with increasing score, while no clear trend was seen for polyunsaturated fat. For all micronutrients increasing intakes were seen with increasing score. This was especially pronounced for vitamin $\mathrm{C}$ and folate. Analysing the data exclusive energy under-reporters resulted, as expected, in a higher total energy intake, but the distributions of macronutrients were the same as when analysing the total group. There was a slightly higher proportion of female under-reporters in the lowest group of diet score, but in general no gender difference was seen regarding under-reporting.

Median intakes (and 25 and 75 percentiles) of selected foods and food groups in men and women are presented in Table 4. Overall men had a higher intake of high fat dairy product compared to women, while women had

Table 2. Characteristic of the population in each of the three groups

\begin{tabular}{|c|c|c|c|c|}
\hline & Lowest group & Intermediary group & Highest group & $p$-value \\
\hline Mean dietary score (range) & $2.8(1.2 ; 3.4)$ & $4.1(3.4 ; 4.7)$ & $5.2(4.7,6.0)$ & \\
\hline Male/Female ratio & $61 / 39$ & $46 / 54$ & $34 / 66$ & $<0.0001^{*}$ \\
\hline Age, y. Mean (SD) & $42(15)$ & $46(15)$ & $51(14)$ & $<0.000 I^{* *}$ \\
\hline Body mass index, kg/m2. Mean (SD) & $25.4(4.3)$ & $24.9(4.0)$ & $25.4(4.3)$ & ns \\
\hline Under-reporters,\% (EI/BMR <I.I) & 20 & 24 & 38 & $<0.0001$ \\
\hline
\end{tabular}

*Chi square.

**Test for trend (Chi square Type III). 
Table 3. Mean and standard deviations (SD) of intakes of macro- and micronutrients in each of the three groups of dietary score, by gender

\begin{tabular}{|c|c|c|c|c|c|c|c|c|c|c|c|c|c|c|}
\hline & \multicolumn{7}{|c|}{ Male } & \multicolumn{7}{|c|}{ Female } \\
\hline & \multicolumn{2}{|c|}{ Lowest group $(N=518$} & \multicolumn{2}{|c|}{ Intermediary $(N=777)$} & \multicolumn{2}{|c|}{ Highest group $(N=27 I)$} & \multirow[b]{2}{*}{$P$ value* } & \multicolumn{2}{|c|}{ Lowest group $(N=320)$} & \multicolumn{2}{|c|}{ Intermediary $(N=901)$} & \multicolumn{2}{|c|}{ Highest group $(N=564)$} & \multirow[b]{2}{*}{$P$ value* } \\
\hline & Mean & Std & Mean & Std & Mean & Std & & Mean & Std & Mean & Std & Mean & Std & \\
\hline Energy, MJ/day & 11 & 3 & 10 & 3 & 9 & 3 & $<0.0001$ & 9 & 2 & 8 & 2 & 7 & 2 & $<0.0001$ \\
\hline Fat $(\mathrm{E} \%)$ & 40 & 6 & 36 & 4 & 31 & 4 & $<0.0001$ & 38 & 6 & 35 & 5 & 30 & 4 & $<0.0001$ \\
\hline Carbohydrate (E\%) & 46 & 6 & 49 & 5 & 53 & 5 & $<0.0001$ & 48 & 6 & 50 & 6 & 53 & 4 & $<0.0001$ \\
\hline Protein (E\%) & 14 & 2 & 16 & 2 & 16 & 2 & $<0.0001$ & 14 & 2 & 15 & 2 & 16 & 2 & $<0.0001$ \\
\hline Added sugar (E\%) & 12 & 7 & 8 & 5 & 6 & 3 & $<0.0001$ & 14 & 7 & 9 & 5 & 7 & 3 & $<0.0001$ \\
\hline Dietary fibre $(\mathrm{g} / \mathrm{MJ})$ & 2 & 0 & 2 & I & 3 & I & $<0.0001$ & 2 & 0 & 2 & I & 3 & I & $<0.0001$ \\
\hline Saturated fat (E\%) & 17 & 3 & 15 & 2 & 12 & 2 & $<0.0001$ & 17 & 3 & 15 & 2 & 12 & 2 & $<0.0001$ \\
\hline Monounsaturated fat (E\%) & 14 & 2 & 13 & 2 & 11 & 2 & $<0.0001$ & 13 & 2 & 12 & 2 & 11 & 2 & $<0.0001$ \\
\hline Polyunsaturated fat (E\%) & 5 & I & 5 & I & 5 & I & 0.0474 & 5 & I & 5 & I & 5 & I & 0.6611 \\
\hline Alcohol (E\%) & 6 & 6 & 8 & 7 & 7 & 7 & 0.0237 & 4 & 5 & 5 & 5 & 5 & 6 & 0.0094 \\
\hline Vitamin A, RE/IO MJ & 1219 & 637 & 1392 & 971 & 1375 & 814 & $<0.0001$ & 1071 & 532 & 1334 & 845 & 1591 & 1094 & $<0.0001$ \\
\hline Vitamin D, mcg//O MJ & 2.8 & 1.8 & 4.3 & 3.7 & 5.5 & 4.4 & $<0.0001$ & 2.7 & 1.8 & 3.7 & 3.0 & 5.6 & 4.4 & $<0.0001$ \\
\hline Vitamin E, TE/IO MJ & 7.2 & 2.4 & 7.9 & 2.2 & 8.8 & 2.5 & $<0.0001$ & 7.5 & 2.2 & 9.2 & 4.1 & 10.2 & 2.8 & $<0.0001$ \\
\hline Thiamin, $\mathrm{mg} / \mathrm{IO} \mathrm{MJ}$ & 1.3 & 0.3 & 1.5 & 0.3 & 1.6 & 0.3 & $<0.0001$ & 1.3 & 0.3 & 1.5 & 0.3 & 1.6 & 0.3 & $<0.0001$ \\
\hline Riboflavin, mg/lO MJ & 1.7 & 0.4 & 2.0 & 0.5 & 2.0 & 0.5 & $<0.0001$ & 1.7 & 0.5 & 1.9 & 0.5 & 2.1 & 0.5 & $<0.0001$ \\
\hline Niacin, NE/IO MJ & 34.0 & 7.1 & 38.2 & 7.9 & 40.6 & 8.1 & $<0.0001$ & 31.2 & 7.8 & 35.6 & 8.4 & 39.2 & 8.1 & $<0.0001$ \\
\hline Vitamin B6, mg/lO MJ & 1.4 & 0.3 & 1.8 & 0.3 & 2.0 & 0.4 & $<0.0001$ & 1.4 & 0.3 & 1.7 & 0.3 & 2.1 & 0.4 & $<0.0001$ \\
\hline Folate, $\mathrm{mcg} / \mathrm{IO} \mathrm{MJ}$ & 277 & 62 & 356 & 97 & 421 & 104 & $<0.0001$ & 293 & 71 & 405 & 162 & 505 & 155 & $<0.0001$ \\
\hline Vitamin $\mathrm{B} / 2, \mathrm{mcg} / 10 \mathrm{MJ}$ & 5.5 & 2.2 & 6.8 & 3.6 & 7.2 & 2.9 & 0.6611 & 4.9 & 2.1 & 5.8 & 2.9 & 6.8 & 3.4 & $<0.0001$ \\
\hline Vitamin C, mg/lO MJ & 78 & 38 & 111 & 50 & 157 & 63 & 0.0094 & 93 & 46 & 146 & 74 & 203 & 88 & $<0.0001$ \\
\hline Calcium, mg/lo MJ & 1062 & 355 & 1150 & 356 & 1209 & 354 & $<0.0001$ & 1216 & 368 & 1336 & 399 & 1437 & 402 & $<0.0001$ \\
\hline Iron, mg/lO MJ & 11 & 3 & 12 & 3 & 14 & 3 & $<0.0001$ & 10 & 2 & 12 & 3 & 13 & 3 & $<0.0001$ \\
\hline Selenium, $\mathrm{mcg} / \mathrm{IO} \mathrm{MJ}$ & 44.0 & 9.7 & 52.1 & 12.2 & 57.5 & 12.0 & $<0.0001$ & 42.3 & 10.0 & 49.8 & 12.0 & 56.9 & 12.6 & $<0.0001$ \\
\hline Zinc, mg/lO MJ & 11.9 & 2.1 & 12.8 & 2.1 & 13.3 & 1.9 & $<0.0001$ & 11.4 & 2.1 & 12.4 & 2.1 & 13.0 & 1.9 & $<0.0001$ \\
\hline
\end{tabular}

*Test for trend (chi square Type III). 
Table 4. Median (med) and inter-quartile range (25-75) of intakes of food and food groups in the three groups of dietary score, in males and females

\begin{tabular}{|c|c|c|c|c|c|c|c|c|c|c|c|c|c|c|c|c|c|c|c|c|}
\hline \multirow[b]{4}{*}{ High-fat dairy } & \multicolumn{10}{|c|}{ Male } & \multicolumn{10}{|c|}{ Female } \\
\hline & \multicolumn{3}{|c|}{ Lowest group $(N=5 \mid 8)$} & \multicolumn{3}{|c|}{ Intermediary $(N=777)$} & \multicolumn{3}{|c|}{ Highest group $(N=274)$} & \multirow{3}{*}{$\begin{array}{l}P \text { value* } \\
<0.000 \text { I }\end{array}$} & \multicolumn{3}{|c|}{ Lowest group $(N=320)$} & \multicolumn{3}{|c|}{ Intermediary $(N=901)$} & \multicolumn{3}{|c|}{ Highest group $(N=564)$} & \multirow{3}{*}{$\frac{P \text { value* }}{<0.0001}$} \\
\hline & \multirow{2}{*}{$\frac{\text { Med }}{25}$} & \multicolumn{2}{|c|}{$25-75$} & \multirow{2}{*}{$\frac{\text { Med }}{22}$} & \multicolumn{2}{|c|}{$25-75$} & \multirow{2}{*}{$\frac{\text { Med }}{14}$} & \multicolumn{2}{|c|}{$25-75$} & & \multirow{2}{*}{$\begin{array}{c}\text { Med } \\
15\end{array}$} & \multicolumn{2}{|c|}{$25-75$} & \multirow{2}{*}{$\frac{\text { Med }}{14}$} & \multicolumn{2}{|c|}{$25-75$} & \multirow{2}{*}{$\frac{\text { Med }}{11}$} & \multicolumn{2}{|c|}{$25-75$} & \\
\hline & & 9 & 56 & & 7 & 43 & & 5 & 32 & & & 5 & 33 & & 5 & 31 & & 3 & 22 & \\
\hline Low-fat dairy & 12 & 0 & 75 & 33 & 0 & 130 & 59 & 10 & 150 & $<0.0001$ & 26 & 0 & 90 & 52 & 5 & 132 & 76 & 17 & 150 & $<0.0001$ \\
\hline Cheese & 21 & 9 & 40 & 22 & 9 & 36 & 22 & II & 35 & 0.4246 & 16 & 6 & 27 & 19 & 9 & 33 & 18 & 9 & 29 & 0.7494 \\
\hline Red meat & 53 & 29 & 85 & 51 & 29 & 77 & 46 & 26 & 69 & $<0.0001$ & 37 & 20 & 57 & 31 & 16 & 50 & 31 & 16 & 47 & 0.0008 \\
\hline Processed meat & 46 & 24 & 70 & 30 & 16 & 49 & 26 & II & 43 & $<0.0001$ & 23 & 13 & 35 & 18 & 9 & 31 & 13 & 7 & 23 & $<0.0001$ \\
\hline Fish & 5 & 0 & 15 & 21 & 8 & 37 & 34 & 21 & 46 & $<0.0001$ & 4 & 0 & 11 & 14 & 5 & 27 & 27 & 18 & 37 & $<0.0001$ \\
\hline Poultry & 15 & I & 39 & 19 & 3 & 40 & 22 & 4 & 41 & 0.2126 & 15 & 1 & 27 & 18 & 4 & 32 & 20 & 5 & 36 & 0.0018 \\
\hline Rice and pasta & 20 & 0 & 49 & 30 & 0 & 61 & 30 & 0 & 65 & 0.0008 & 19 & 0 & 40 & 20 & 0 & 43 & 15 & 0 & $4 I$ & 0.9585 \\
\hline Fats & 53 & 37 & 75 & 37 & 26 & 49 & 25 & 15 & 34 & $<0.0001$ & 37 & 26 & 50 & 28 & 19 & 38 & 20 & 13 & 27 & $<0.0001$ \\
\hline Rye bread & 62 & 33 & 102 & 70 & 40 & 106 & 90 & 54 & 123 & $<0.0001$ & 35 & 18 & 56 & 47 & 26 & 75 & 57 & 35 & 83 & $<0.0001$ \\
\hline Brown bread & 0 & 0 & 17 & 11 & 0 & 34 & 17 & 0 & 49 & $<0.0001$ & 7 & 0 & 23 & 17 & 2 & 40 & 23 & 6 & 49 & $<0.0001$ \\
\hline White bread & 66 & 41 & 99 & 56 & 26 & 81 & 39 & 17 & 64 & $<0.0001$ & 51 & 30 & 75 & 36 & 17 & 60 & 26 & 13 & 47 & $<0.0001$ \\
\hline Breakfast cer. & 0 & 0 & 25 & 9 & 0 & 39 & 18 & 0 & 45 & $<0.0001$ & 3 & 0 & 20 & 7 & 0 & 31 & 14 & 0 & 39 & $<0.0001$ \\
\hline Fruit & 88 & 32 & 150 & 154 & 76 & 256 & 275 & 173 & 401 & $<0.0001$ & 102 & 51 & 172 & 199 & 123 & 302 & 288 & 202 & 417 & $<0.0001$ \\
\hline Vegetables & 113 & 75 & 164 & 134 & 95 & 196 & 170 & 120 & 232 & $<0.0001$ & 100 & 70 & 150 & 146 & 106 & 208 & 186 & 133 & 265 & $<0.0001$ \\
\hline Juice & 0 & 0 & 51 & 26 & 0 & 103 & 26 & 0 & 154 & $<0.0001$ & 0 & 0 & 77 & 26 & 0 & 103 & 26 & 0 & 124 & 0.2676 \\
\hline Potatoes & 111 & 61 & 173 & 112 & 58 & 176 & 119 & 75 & 180 & 0.0569 & 73 & 40 & 107 & 67 & 34 & 103 & 70 & 37 & 117 & 0.0412 \\
\hline Water & 343 & 57 & 764 & 543 & $17 \mid$ & 1000 & 686 & 371 & 1229 & $<0.0001$ & 600 & 200 & 1157 & 914 & 514 & 1414 & 1057 & 714 & 1600 & $<0.0001$ \\
\hline Beer & 189 & 47 & $47 \mid$ & 189 & 47 & 424 & 94 & 47 & 283 & $<0.0001$ & 0 & 0 & 94 & 0 & 0 & 94 & 0 & 0 & 47 & 0.0048 \\
\hline Wine & 40 & 0 & 124 & 80 & 7 & 197 & 89 & 16 & 200 & $<0.0001$ & 25 & 0 & 110 & 60 & 0 & 149 & 65 & 0 & 144 & 0.0031 \\
\hline Soft drinks & 186 & 14 & 457 & 57 & 0 & 186 & 0 & 0 & 71 & $<0.0001$ & 143 & 0 & 386 & 29 & 0 & 114 & 0 & 0 & 50 & $<0.0001$ \\
\hline Sweets etc. & 13 & 0 & 32 & 9 & 0 & 23 & 4 & 0 & 15 & $<0.0001$ & 21 & 8 & 44 & 14 & 4 & 27 & 8 & I & 19 & $<0.0001$ \\
\hline Cake etc. & 52 & 22 & 97 & 40 & 17 & 77 & 34 & 14 & 62 & $<0.0001$ & 53 & 29 & 83 & 47 & 22 & 75 & 32 & 14 & 56 & $<0.0001$ \\
\hline
\end{tabular}

*Test for trend (chi square Type III). 
higher intake of low fat dairy. However, in both genders, intake of high fat dairy products decreased with increasing score, while intake of low-fat dairy products increased with increasing score. Intakes of red meat, processed meat and white bread were highest in the lowest quartile of diet score, while intakes of fish, poultry and rye bread and wholemeal bread were highest in the highest quartile. As expected from the construction of the index, intakes fish and of fruits and vegetables increased with increasing score. Individuals in the highest quartile had higher intakes of wine, while individuals in the lowest quartile had highest intakes of beer and soft drinks. Small reductions were seen in intake of potatoes with increasing score, while there was no clear trend regarding intakes of cheese, rice and pasta in the three groups.

\section{Discussion}

In this study the habitual diet of a representative sample of the Danish adult population was presented. Furthermore, a diet quality index was developed based the national FBDG in order to evaluate the overall quality of the diet regarding both intakes of foods and nutrients.

Overall the results from the present study indicate that there is room for improvement regarding macronutrient distribution in the diet of the Danish population. Mean energy contribution from fat of max $30 \mathrm{E} \%$ was obtained only in the highest quartile in the women, and in none of the groups, saturated fat $\mathrm{E} \%$ of maximum $10 \%$ was reached. The decrease in energy contribution from fat with increasing score was mainly reflected in the carbohydrate intake, while contribution of energy from protein did not vary markedly between the groups. For both men and women intake of dietary fibre was sufficient only in the highest group, while intake of added sugar was too high in the lowest group. Only in the highest quartile the median fish intake was close to the recommended level ( $28 \mathrm{~g} /$ day corresponding to $196 \mathrm{~g} /$ week). Women had a higher intake of fruit than men, but median intake of fruit and vegetables did not reach the recommended level in any of the groups. In general, compliance with the FBDG was low, as has also been reported in other countries (19-21).

The highest proportion of under-reporters was detected in the group with the highest diet score, i.e. the group of individuals with diets closest to the FBDG. Winkvist et al. (22) found a higher degree of underreporting among individuals classified as having healthy eating patterns ('fruit and vegetables' pattern), and explained the higher proportion of under-reporting with an accompanying higher degree of overweight in this group. As we found no difference in mean BMI in the three groups of diet score, this explanation cannot be applied to our results. When analyzing the data excluding the under-reporters, total energy intake was, as expected slightly higher, but distribution of macronutrients were similar as when analyzing the whole group.

Total energy intake decreased with increasing diet quality score. This is opposite to what was reported by Thiele (8), who explained the higher energy intake with increasing score with the fact that the more food an individual eats (and thereby total energy intake), the more likely the individual is in reaching the recommended intake levels for a number of nutrients. As the focus in the present study was assessment of the quality and not the quantity of the diet, the index was constructed on basis of energy-adjusted intakes, which can explain the opposite findings. In addition, we found increasing nutrient density with increasing score, indicating that following the dietary guidelines will lead to a more nutrient-dense diet, which has also been found in a study using a diet index to investigate the risk of major chronic diseases (23). The increase was particularly seen in vitamin $\mathrm{C}$ and folate probably due to the higher intake of fruit and vegetables, which are elements in the index. Regarding intake of Vitamin D, all three groups had a mean intake below $7.5 \mathrm{mcg} / \mathrm{day}$, which is the recommended intake by NNR. However, the mean intake in the group with the highest score was $(6.0 \mathrm{mcg} / \mathrm{day})$, which is close to the recommended intake. Iron intake increased with increasing score, but the mean intake in women was however below recommended level for women of childbearing age in all the groups ( $15 \mathrm{mg} / \mathrm{day})$, so even when having a diet closest to the FBDG women of childbearing age may still be a group at risk of insufficient intakes of iron. Mean iron intake was above the recommended level for men.

Differences in intakes of food groups may give more insight into which food groups are selected by individuals with better or poorer diet quality respectively. Increasing intakes of 'healthy foods', such as low-fat dairy products, fish, poultry, rye bread, fruit and vegetables were detected with higher scores. In addition, intakes of less healthy food groups, such as high-fat dairy products, red and processed meat, white bread, soft drinks, sweets and cakes decreased with increasing scores. Furthermore, the intake of low-fat milk products is lowest in this group, indicating a shift in milk habits from high fat to low fat across the index, as was also found in a study of UK consumers (24). Intake of added sugar was high in the lowest group, which is expressed by the higher intake of sugar-sweetened soft drinks in the lowest group, which in addition has the lowest intake of water, suggesting that water may be replaced with less healthy alternatives. Wine intake is highest in the high group of index score, while consumption of beer is highest in the low group of index score. These results are in line with previous studies of associations between dietary intake and alcohol consumption in Danes, where wine consumption was associated with higher intake of fish, fruit and vegetables, and olive oil (25). One of the FBDG's is 'Drink water when 
you are thirsty'. This guideline was not included in the diet quality index, but nevertheless intake of water increased with increasing score, indicating a more healthy lifestyle and higher probability of following the dietary guidelines. The increasing intake of healthy foods with increasing score has also been described by others $(5,26)$. The findings may contribute to the knowledge on which food items are related to healthy eating habits, and may be a useful tool in communicating messages on healthy diet habits.

The construction of the diet quality index results in a score reflecting compliance towards the FBDG, and thus allows the total score to represent the degree to which the individuals meet the FBDG, as it may be relevant to distinguish between individuals with intakes near the cutoff values and those with intakes far from the FBDG (27). One potential problem in creating an index from several intakes of nutrients and foods is that intakes are internally correlated, e.g. an individual having a high intake of saturated fat is also likely to have a high intake of total fat. Likewise, individuals eating a diet rich in fruit and vegetables are more likely to have lower intakes of fat, than individuals eating less fruit and vegetables. However, one of the purposes of this study was to evaluate the diet quality in Danish adults in relation to the FBDG, which comprise advices on reducing both total fat intake and intake of foods rich in saturated fat, as well as other foods/nutrients that are likely to be correlated, justifying inclusion of several correlated foods and nutrients in the diet quality index. Also some researchers add weights to the items included in their diet indices according to their expected health effect, but as the purpose of this study was to evaluate the overall diet quality based on the FBDG and not the potential health effect of the individual guidelines all included items were weighted equally.

Despite having had FBDG for more than 30 years, a substantial proportion of the population had a diet quality that did not reflect the guidelines. As Denmark is experiencing an increase in the prevalence of overweight and obesity (28-30), one approach in improving public health may be an increased effort to increase the compliance towards the FBDG. One approach is to increase the knowledge to and awareness on the FBDG, which are both prerequisites in a successful nutrition intervention. In the present study eating a diet with a high diet quality index, i.e. following the FBDG was associated with increasing age and being female. The finding that some groups may be more susceptible in the distribution of nutrition messages has also been described in other studies on diet quality assessment $(4,8,31,32)$, and suggest more focus to potentially vulnerable groups in nutritional education.

A major strength of this study is that data were collected throughout the country covering a wide age range of adults, providing a description of dietary intake in all areas of Denmark, and thus not restricted to certain areas or rates of urbanisation. A limitation of the study is the participation rate of approximately $50 \%$ raising the question of representativeness of the study sample. Results from earlier analyses indicated that the sample was representative of the Danish population with respect to education; however, the younger men were slightly under-represented (12). Under-representation may potentially lead to selection bias, as non-participants in dietary studies are likely to eat a diet that differs from the diet of participants (33). If non-participants are expected to have a diet that to a lesser degree comply with FBDG, this would lead to a greater variation in dietary intake in the highest vs. the lowest group of diet index, i.e. the variation in healthy and less healthy food between the groups would have been even more pronounced.

\section{Conclusion}

The diet quality index developed in this study has shown to be valuable in evaluating the dietary quality in relation to the national dietary guidelines. Distribution of macronutrients leaves room for improvement, while intakes of micronutrient were generally sufficient in all ranges of the score, except vitamin D, and iron in women of childbearing age. Furthermore, the diet quality index may be a useful tool in future studies investigating variations in dietary intakes with respect to lifestyle factors, and attitudes towards healthy eating, socio-demographic and regional differences in Denmark (34).

\section{Acknowledgements}

The authors would like to thank Hanne-Jette Hinsch and Tue Christensen for processing the data. Managerial team of the Danish National Survey of Diet and Physical Activity consists of Sisse Fagt, Jeppe Matthiessen, Margit Groth, Mette Rosenlund Sørensen, Vibeke K. Knudsen and Ellen Trolle.

\section{Conflict of interest and funding}

The authors have not received any funding or benefits from industry or elsewhere to conduct this study.

\section{References}

1. Robertson A, Tirado C, Lobstein T, Jermini M, Knai C, Jensen $\mathrm{JH}$, et al. Food and health in Europe: a new basis for action. Rome: World Health Organization; 2004. No. 96.

2. Astrup A, Lyhne N, Stender S, Trolle E. Kostrådene 2005. Søborg, Denmark: Ernæringsrådet og Danmarks Fødevareforskning; 2005. No. 36.

3. Alexander J, Andersen SA, Aro A, Becker W, Fogelholm M, Lyhne N, Meltzer HM, Pedersen AN, Pedersen JI, Thorsdottir I, eds. Nordic Nutrition Recommendations 2004. Integrating nutrition and physical activity. 4th edition. Copenhagen: Nordic Council of Ministers; 2004. 
4. Biltoft-Jensen A, Fagt S, Groth MV, Matthiessen J, Wachmann HC, Christensen T. The intake of saturated fat and dietary fibre: a possible indicator of diet quality. Br J Nutr 2008; 100: 624-32.

5. Kennedy ET, Ohls J, Carlson S, Fleming K. The healthy eating index: design and applications. J Am Diet Assoc 1995; 95: 1103-8.

6. Harnack L, Nicodemus K, Jacobs DR, Jr, Folsom AR. An evaluation of the dietary guidelines for Americans in relation to cancer occurrence. Am J Clin Nutr 2002; 76: 889-96.

7. George GC, Milani TJ, Hanss-Nuss H, Freeland-Graves JH. Compliance with dietary guidelines and relationship to psychosocial factors in low-income women in late postpartum. J Am Diet Assoc 2005; 105: 916-26.

8. Thiele S, Mensink GB, Beitz R. Determinants of diet quality. Public Health Nutr 2004; 7: 29-37.

9. Vandevijvere S, De Vriese S, Huybrechts I, Moreau M, Temme E, De Henauw S, et al. The gap between food-based dietary guidelines and usual food consumption in Belgium, 2004. Public Health Nutr 2009; 12: 423-31.

10. McNaughton SA, Ball K, Crawford D, Mishra GD. An index of diet and eating patterns is a valid measure of diet quality in an Australian population. J Nutr 2008; 138: 86-93.

11. Kant AK. Indexes of overall diet quality: a review. J Am Diet Assoc 1996; 96: 785-91.

12. Pedersen AN, Fagt S, Groth MV, Christensen T, Biltoft-Jensen A, Matthiessen J, et al. Danskernes Kostvaner 2003-2008. Hovedresultater. Søborg, Denmark: DTU Fødevareinstituttet; 2010.

13. Biltoft-Jensen A, Matthiessen J, Rasmussen LB, Fagt S, Groth MV, Hels O. Validation of the Danish 7-day pre-coded food diary among adults: energy intake $v$. energy expenditure and recording length. Br J Nutr 2009; 102: 1838-46.

14. Rasmussen LB, Matthiessen J, Biltoft-Jensen A, Tetens I. Characteristics of misreporters of dietary intake and physical activity. Public Health Nutr 2007; 10: 230-7.

15. Knudsen VK, Gille MB, Nielsen TH, Christensen T, Fagt S, Biltoft-Jensen A. Relative validity of the pre-coded food diary used in the Danish National Survey of Diet and Physical Activity. Public Health Nutr 2011; 14: 1-7.

16. Volatier JL, Biltoft-Jensen A, De Henauw S, Gibney MJ, Huybrechts I, McCarthy SN, et al. A new reference method for the validation of the nutrient profiling schemes using dietary surveys. Eur J Nutr 2007; 46(Suppl 2): S29-S36.

17. SAS Institute Inc. SAS Enterprise Guide. NC, USA: Cary; 2006; 4.1.

18. Goldberg GR, Black AE, Jebb SA, Cole TJ, Murgatroyd PR, Coward WA, et al. Critical evaluation of energy intake data using fundamental principles of energy physiology: 1. Derivation of cut-off limits to identify under-recording. Eur J Clin Nutr 1991; 45: 569-81.

19. Ball K, Mishra GD, Thane CW, Hodge A. How well do Australian women comply with dietary guidelines? Public Health Nutr 2004; 7: 443-52.

20. Becker W. Dietary guidelines and patterns of food and nutrient intake in Sweden. Br J Nutr 1999; 81(Suppl 2): S113-7.
21. Castetbon K, Vernay M, Malon A, Salanave B, Roudier C, Oleko A, et al. Dietary intake, physical activity and nutritional status in adults: the French nutrition and health survey (ENNS, 2006-2007). Br J Nutr 2009; 102: 733-43.

22. Winkvist A, Hornell A, Hallmans G, Lindahl B, Weinehall L, Johansson I. More distinct food intake patterns among women than men in northern Sweden: a population-based survey. Nutr J 2009; 8: 12.

23. Estaquio C, Castetbon K, Kesse-Guyot E, Bertrais S, Deschamps V, Dauchet L, et al. The French National Nutrition and Health Program score is associated with nutritional status and risk of major chronic diseases. J Nutr 2008; 138: 946-53.

24. Wearne SJ, Day MJ. Clues for the development of food-based dietary guidelines: how are dietary targets being achieved by UK consumers? Br J Nutr 1999; 81(Suppl 2): S119-S26.

25. Tjonneland A, Gronbaek M, Stripp C, Overvad K. Wine intake and diet in a random sample of 48763 Danish men and women. Am J Clin Nutr 1999; 69: 49-54.

26. Cosgrove M, Flynn A, Kiely M. Consumption of red meat, white meat and processed meat in Irish adults in relation to dietary quality. Br J Nutr 2005; 93: 933-42.

27. Waijers PM, Feskens EJ, Ocke MC. A critical review of predefined diet quality scores. Br J Nutr 2007; 97: 219-31.

28. Matthiessen J, Groth MV, Fagt S, Biltoft-Jensen A, Stockmarr A, Andersen JS, et al. Prevalence and trends in overweight and obesity among children and adolescents in Denmark. Scand J Public Health 2008; 36: 153-60.

29. Due P, Heitmann BL, Sorensen TI. Prevalence of obesity in Denmark. Obes Rev 2007; 8: 187-9.

30. Bendixen H, Holst C, Sorensen TI, Raben A, Bartels EM, Astrup A. Major increase in prevalence of overweight and obesity between 1987 and 2001 among Danish adults. Obes Res 2004; 12: 1464-72.

31. Patterson RE, Haines PS, Popkin BM. Diet Quality Index: Capturing a multidimensional behavior. J Am Diet Assoc 1994; 94: 57-64.

32. Fogli-Cawley JJ, Dwyer JT, Saltzman E, McCullough ML, Troy LM, Jacques PF. The 2005 dietary guidelines for Americans Adherence Index: development and application. J Nutr 2006; 136: 2908-15.

33. Margetts BM, Nelson M, eds. Design concepts in nutritional epidemiology. New York, NY: Oxford University Press; 1997.

34. Dubois L, Girard M, Bergeron N. The choice of a diet quality indicator to evaluate the nutritional health of populations. Public Health Nutr 2000; 3: 357-65.

\footnotetext{
*Vibeke K. Knudsen

Division of Nutrition

National Food Institute

Mørkhøj Bygade 19

DK-2860 Søborg

Denmark

Tel: +4535887414

Email: vkkn@food.dtu.dk
} 